\title{
Belting Pós Rent: um estudo sobre a evolução do canto do teatro musical norte-americano
}

\author{
Adrielly Oissa \\ Universidade Federal da Integração Latino-Americana/UNILA, Foz do Iguaçu, Brasil \\ E-mail: oissa.adrielly@gmail.com
}

Resumo

Observando os relatos sobre a tragédia vocal que aconteceu no musical Rent de 1996, quando grande parte do elenco perdeu a voz, e com base nos estudos de Schutte e Miller (1992), Popeil (1999), Edwin (2007), Durham-Lozaw (2014) e Silva (2016) sobre a voz do belt, a autora propõe uma reflexão a respeito do ensino do canto do teatro musical norte-americano e as transformações sofridas na pedagogia vocal do belt ao longo dos anos. Para tal, foram analisadas duas interpretações de uma mesma canção do musical Rent, executadas pela mesma cantora em um intervalo de 10 anos, uma em 1996 e outra em 2006 e, duas interpretações de uma mesma canção do musical Cabaret, uma executada em 1972 e outra em 2015. Os resultados desse estudo mostram que houve significativa mudança na pedagogia vocal do canto de teatro musical norte-americano, o que proporciona aos cantores de teatro musical contemporâneo, menor risco de sofrerem com problemas vocais causados pelo uso inadequado da voz. Além disso, mostram a importância de que professores de canto e especialistas em voz cantada conheçam a fisiologia vocal na produção do belting e saibam como executar e aplicar a técnica aos seus alunos.

Palavras-chave

Belting. Canto. Teatro Musical. Técnica Vocal. Pedagogia Vocal.
Abstract

Looking at reports of the vocal tragedy that happened in the musical Rent of 1996, when much of the cast lost its voice, and based on studies by Schutte and Miller (1992), Popeil (1999), Edwin (2007), Durham-Lozaw (2014) and Silva (2016) on the voice of the belt, the author proposes a reflection on the teaching of the singing of North American musical theater and the transformations undergone in the vocal pedagogy of the belt over the years. For that, two interpretations of the same song of the musical Rent, executed by the same singer in an interval of 10 years, one in 1996 and one in 2006 and, two interpretations of a same song of the musical Cabaret, one executed in 1972 and another in 2015. The results of this study show that there was a significant change in the vocal pedagogy of North American musical theater singing, which gives contemporary musical theater singers a lower risk of suffering from vocal problems caused by improper voice use. In addition, they show the importance of singing teachers and vocal-speaking experts to know the vocal physiology in belting production and to know how to perform and apply the technique to their students.

Keywords

Belting. Singing. Musical Theater. Vocal Technique. Vocal Pedagogy. 


\section{Introdução}

A junção de teatro e música é uma tradição antiga e pode receber diversos nomes dependendo de seu contexto, gênero, época, país de origem e técnica vocal: ópera, opereta, óperas bufas, burlesco, comédia musical, teatro musical, dentre outros. Segundo Kenrick, o teatro musical da Broadway como conhecemos hoje teve início com as operetas, vindas da ópera cômica francesa e vienense do século XIX (KENRICK, 2008). Elizabeth Ann Benson diz que "as habilidades técnicas requeridas dentro de um determinado gênero musical são determinadas pelo contexto estético do repertório alvo" (BENSON, 2018, p.10, tradução nossa $\left.{ }^{1}\right)^{2}$. Gerald Bordman em seu livro "American musical theatre: A chronicle" diz que os estilos de canto do musical norte-americano contemporâneo originaram-se de duas fontes distintas: primeiro da tradição do "bel canto" e, posteriormente, da tradição folclórica afro-americana, incorporada nos estilos de música popular do país, como vaudeville, jazz e blues (BORDMAN, 2001).

$O$ belting apareceu na Broadway na década de 1940 nas vozes de cantoras como Ethel Merman, Celeste Holm e Judy Garland como uma alternativa ao legit ${ }^{3}$ (WELLS, 2006). Na época, o belting era um recurso timbrístico característico de personagens cômicos ou caricatos enquanto que as heroínas, as protagonistas românticas ainda utilizavam a voz legit. Segundo Scott Miller, Ethel Merman foi a primeira dentre várias mulheres, cantoras de teatro musical, que rejeitavam a prática de cantar em voz de

\footnotetext{
1 "The technical skills required within a given musical genre are determined by the aesthetic context of the target repertoire."

2 Todas as traduções deste artigo foram feitas pela autora.

3 Legit vem de "legitimate voice", ou seja, a "voz legítima" lírica". É semelhante ao canto lírico tradicional. Nessa época o canto lírico era considerado como a "voz legítima".
}

cabeça como cantoras de ópera e, em vez disso, "cantavam" suas canções de maneira forte, agressiva e com voz de peito, dando origem a uma nova maneira de se cantar na Broadway (MILLER, 2007). A pesquisadora e especialista em belting Lisa S. Popeil diz que "...a tradição do "bel canto" colocou em questão a validade artística, a saúde e até mesmo o valor estético desse poderoso uso da voz" (POPEIL, 1999, p.27). Robert Edwin em seu artigo "Belt is Legit" fala sobre o modo com que o belting foi visto na academia e entre os apreciadores da música chamada "erudita". Ele diz que o belting "era visto como "não culto", comercial e, de certa forma, o filho bastardo do canto autêntico ${ }^{5 \text { " }}$ (EDWIN 2007, p.213).

O belting passou por transformações ao longo dos anos e alcançou grande sucesso em todo o mundo, hoje ele é conhecido como "a voz da Broadway" mesmo não sendo uma técnica exclusiva de teatro musical. Segundo Edwin “.... belting está lentamente ganhando credibilidade como uma forma de arte vocal viável e legítima, digna de estudo médico e científico, apoio pedagógico e crítica artística" (EDWIN 2007, p.213). Neste estudo, analisarei as mudanças ocorridas na execução do belting, observando os avanços nos estudos científicos sobre a fisiologia vocal e as mudanças na pedagogia do canto de teatro musical. Para isso, tendo em consideração o fato de que é preciso partir de algum ponto, tomarei como um marco na transição da técnica, o musical Rent pois e chamou a atenção o relato encontrado no

\footnotetext{
4 “...Bel Canto tradition has brought into question the artistic validity, healthfulness, and even aesthetic value of this powerful use of the voice."
} 
livro Strike Up The Band, de Scott Miller, onde diz que grande parte do elenco sofreu de problemas vocais durante sua estréia na Broadway em 1996.

\section{Belting antes e depois de Rent}

\section{O termo belting vem do verbo "to belt} ouf', que significa cantar de maneira forçada ou gritada. Hoje o belting é conhecido como um canto que utiliza voz mista de peito $(\text { chest } m i x)^{7}$ com predominância do sub registro de peito, cantado em "forte" nas regiões média e aguda da voz feminina, sendo que, na voz masculina é cantado somente na região aguda da voz. É produzido com a laringe em posição natural, faringe estreita e com a boca e a mandíbula bem abertas, caracterizando um som mais brilhante, frontal e metálico. No agudo, a partir do $\mathrm{C}^{8}$, o belting é conhecido como high belt.

Até o início dos anos 90 havia poucos estudos sobre belting. Nessa época, o belting era considerado por professores de canto classicamente treinados, que eram absoluta maioria, como prejudicial à saúde da voz. Edwin sugeriu que esta polêmica em torno do belting se desenvolveu porque os pedagogos de voz classicamente treinados não tinham informação suficiente sobre a técnica e a fisiologia vocal no belting (EDWIN, 1998). Essa falta de estudos relevantes a respeito do belting e a grande reticência dos professores de canto lírico

\footnotetext{
7 "A voz mista, ou mix pode também ser dividida de acordo com qual musculatura esteja mais presente ou "dominante": se for o músculo cricotireóideo $(\mathrm{CT})$, será uma voz mista com predominância de voz de cabeça, ou seja, um head-mix; se for o músculo tireoaritenóideo (TA), será uma voz mista com predominância de voz de peito, ou seja, um chest-mix" (SILVA, 2016, p.198)..

8 Neste estudo, consideramos o Dó central como C3 que é a nomenclatura mais comum no Brasil, diferente da nomenclatura tradicional norte-americana que coloca o Dó central como C4. Assim sendo, o C4 descrito no texto é o da nomenclatura brasileira e refere-se ao C5 na nomenclatura norte-americana.
}

em aprender para ensinar sobre essa técnica fez com que muitos cantores sofressem com problemas vocais enquanto tentavam se adequar às exigências do teatro musical que cada vez mais buscava artistas completos, capazes de cantar para grandes platéias, atuar e dançar.

No dia 29 de abril de 1996, estreou na Broadway o musical Rent, de Jonathan Larson. Rent tornou-se um divisor de águas na história dos musicais, o show tornou-se um fenômeno cultural, além de trazer nova vida comercial aos musicais da Broadway, também trouxe para o teatro um público mais jovem, graças a sua temática e produção inovadoras e por colocar fim ao grande divisor entre a música pop e a música de teatro que existia desde a chegada do rock and roll na década de 1950. Ao pesquisar a história do teatro musical, mas especificamente a trajetória dos cantores de teatro musical, deparei-me com um relato a respeito do elenco original de Rent que chamou a minha atenção e, aguçou o desejo de me aprofundar sobre o tema da pedagogia vocal ofertada aos cantores de teatro musical. Segundo Miller, durante uma apresentação, nove dos principais membros do elenco estavam em repouso vocal (MILLER, 2007).

De fato, os desafios musicais de Rent
e o estilo rock and roll de performance
fizeram com que dezenas de atores es-
tivessem se machucando vocalmente
fazendo o show, ficando com fadiga vo-
cal severa, adquirindo nódulos em suas
pregas vocais, ou apenas ficando do-
entes pelo esforço de fazer o show oito
vezes por semana. Alguns comentaris-
tas sugeriram que Rent poderia arruinar
toda uma geração de jovens atores de
musicais da Broadway (MILLER, 2007,
p.191-192)

9 "In fact, Rent's musical challenges, and the rock and roll style of performance, meant that dozens of actors were hurting themselves vocally performing the show, getting severe vocal fatigue, getting nodes on their vocal cords, or just getting sick from the exertion of the doing the show eight times a week. Some com- 
Infelizmente não encontrei nenhum outro relato mais profundo sobre o ocorrido com o elenco de Rent, nem qualquer informação sobre a existência ou não de um preparador vocal para o elenco. Sabemos, porém, que o que aconteceu em Rent já vinha acontecendo há algum tempo com os cantores de teatro musical, por esse motivo, decidi tomar, para essa pesquisa, o ano de estreia de Rent como um marco na transição da técnica vocal ensinada aos cantores de teatro musical no tocante a produção do belting.

Segundo Trinquesse, muitas dessas lesões vocais que vinham sendo sofridas pelos cantores de teatro musical, na tentativa de produzir o belting, podem ter acontecido pelo fato de que "...muitos estariam experimentando esse estilo de canto, sozinhos, por imitação, na maior parte do tempo forçando suas vozes sem ser acompanhados por um profissional da voz"10 (TRINQUESSE, 2009, p.2).

Com relação à pedagogia vocal da época, considerando que esta acompanha os estudos e pesquisas científicas sobre a voz, devemos ter em mente que a formação dos professores de canto era, em sua maioria, em canto lírico e que estes professores não tinham interesse nem conhecimento para ensinar outro tipo de técnica vocal que não fosse a da "voz legítima". Não havia professores de canto que soubessem como ensinar a produzir o belting e, principalmente, como fazê-lo de maneira saudável. Segundo a pesquisadora Susan Durham-Lozaw "...os primeiros estudos limitaram-se a indivíduos únicos, e os pesquisadores questionaram a generalização dos resultados de tais es-

$\overline{\text { mentators suggested that Rent might just ruin a whole genera- }}$ tion of young Broadway musical actors."

10 “...nombre d'entre eux expérimentent ce style de chant par eux-mêmes, par imitation, la plupart du temps en forçant sur leurs voix et sans être encadrés par un professionnel de la voix." tudos"11 (DURHAM-LOZAW, 2014, p.15). Contudo, esses estudos como os de Estill (1988), Schutte e Miller (1993), entre outros, contribuíram significativamente para o aprimoramento da técnica como a conhecemos hoje e levaram a uma maior compreensão dos mecanismos vocais envolvidos na transição entre os sub-registros de peito e de cabeça, o que é essencial no desempenho do teatro musical. Além disso, surgiram diversas pesquisas relacionadas à produção da voz do belt em termos de seu impacto na saúde vocal do cantor e a necessidade de o professor de canto clássico incluir técnicas de belting como parte de seu ensino.

$\mathrm{Em}$ entrevista fornecida à Susan Durham-Lozaw, Jeannette LoVetri e Lisa Popeil, professoras de canto e especialistas em canto popular norte-americano do século XXI, falaram sobre a importância de ter conhecimento acerca da técnica que estão ensinando a seus alunos. Segundo Popeil, o professor deve ser capaz de explicar a mecânica por trás do que o aluno está fazendo e, em uma linguagem que ele possa entender (DURHAM-LOZAW, 2014). Neste contexto, LoVetri expressou: "...se você não fizer isso, você não deve ensiná-lo, e se você não sabe as diferenças entre o canto clássico e o do teatro musical, você não deve ensinar as diferenças ${ }^{12 "}$ (DURHAM-LOZAW 2014, p.74). Popeil declarou: "Conheço muitos professores que não percebem que a imitação é o principal estilo de aprendizagem para os alunos e, se eles não puderem mostrar o que o aluno precisa fazer, é o aluno que sofre com o resultado" (idem) ${ }^{13}$.

11 "...early studies were limited to single subjects, and researchers have questioned the generalizability from the results of such studies."

12 “...if you don't do it, you shouldn't teach it, and if you don't know the differences between classical and music theater singing, you shouldn't teach the differences" - Jeannette LoVetri.

13 "I've known too many teachers who don't realize that imitation 
Graças ao avanço nos estudos e pesquisas sobre belting, também ao fato de que muitos professores têm se especializado na prática dessa técnica, os cantores de teatro musical encontram hoje uma vasta gama de profissionais capazes de ensiná-los e auxiliá-los. Deste modo, o belting hoje é praticado com menos esforço vocal e timbre mais briIhante. Silva diz que:

O belt hoje apresenta mais liberdade na produção sonora, menos esforço, pouco vibrato e som brilhante (frontal), mas sem [a] sensação de precariedade ou fragilidade encontrada antes. $O$ timbre é predominantemente definido pela presença atuante do músculo tiro-aritenóideo (TA) em uma espécie de voz mista (chamada em inglês de mix) dominada por TA (chest mix) podendo chegar até G4 (SILVA, 2016, p.2).

\section{Fisiologia vocal na produção do Belting}

O teatro musical contemporâneo exige uma técnica forte, um amplo alcance vocal, agilidade na articulação das palavras e suavidade na transição entre as regiões grave, média e aguda do sub registro de peito. Além disso, Silva diz que "...no belting, se utiliza muito o "straight tone ${ }^{14 ",}$ com o vibrato postergado, geralmente no fim da nota sustentada, semelhante à música antiga e ao jazz"' (SILVA, 2016, p.3).

Jo Estill foi uma das pioneiras no estudo sobre belting e a primeira a comparar a fala, o belting e o canto clássico de maneira científica. Ela afirmou:

is the primary learning style for students and, if they then can't show what the student needs to do, it is the student who suffers as a result" - Lisa Popeil.

14 "Straight tone" em português "tom reto", ou seja, quando se canta com controle do fluxo de ar fazendo com que a nota sustentada soe sem vibratos, lisa, reta.
Uma mensagem é clara nesta comparação da área de contato glotal (fase fechada) do ciclo vibratório, da EMG ${ }^{15}$ das pregas vocais e da EMG média dos músculos extrínsecos testados: inequivocamente, essas três qualidades [fala, belting e canto clássico] representam três modos diferentes de produção da voz (ESTILL, 1988, p.40-41) ${ }^{16}$.

Estill observou que houve aumento na atividade muscular tanto intrínseca quanto extrínseca da laringe para belting e sugeriu que o belting apresenta maior esforço vocal em relação ao canto clássico (ESTILL, 1988). O coeficiente de fechamento $\left(\mathrm{CQ}^{17}\right)$ das pregas vocais é mais elevado no belting do que no canto clássico. Segundo Silva, isso deixa claro que há "maior tensão fonatória, pressão subglótica mais alta, níveis de pressão sonora mais altos, mais tensão na musculatura extrínseca e maiores níveis de adução das PPVV" (SILVA, 2016, p.200) ${ }^{18}$.

Schutte e Miller observaram uma fase glótica fechada mais longa, pressão pulmonar aumentada e uma elevação do primeiro formante ${ }^{19}$ em direção à freqüência do se-

\footnotetext{
15 Sigla utilizada para se referir à "eletromiografia", um método de diagnóstico que avalia problemas nervosos ou musculares. Utiliza eletrodos de superfície para avaliar a capacidade das células nervosas de transmitirem sinais elétricos ou, eletrodos em forma de agulha para avaliar a atividade muscular em repouso ou durante a contração muscular.
}

16 "A message is clear in this comparison of the glottal contact (closed phase) area of the vibratory cycle, the EMG of the vocal folds, and the mean EMG of the extrinsic muscles tested: unequivocally, these three qualities [speech, belting and classical singing] represent three modes different voice production ".

17 "closing coefficient" coeficiente de fechamento das pregas vocais (PPVV).

18 Tenores clássicos tem $C Q$ equivalente ao belting quando cantam forte na região aguda.

19 Os formantes determinam a qualidade das vogais e contribuem muito para o timbre pessoal do cantor (CORDEIRO, PINHO E CAMARGO, 2007). O formante é representado pelas frequências naturais de ressonância do trato vocal, especificamente na posição articulatória da vogal falada. As vogais são identificadas pelos seus formantes (BEHLAU, 2001). Os formantes são expressos através de seu valor médio em Hertz $(\mathrm{Hz})$. O primeiro formante (F1) ocorre na cavidade posterior da 
gundo e afirmaram que a laringe mais alta e a língua levantada, que são características do canto belt, são consistentes com as freqüências mais altas do primeiro formante (F1). Observando uma cantora de teatro musical, afirmaram que o propósito de elevar a F1 seria para ajustá-la próximo ao segundo harmônico ${ }^{20}(\mathrm{H} 2)$. Também verificaram que belters usavam o trato vocal, ressonâncias e formantes, diferentemente de cantores classicamente treinados. Em particular, verificou-se que o segundo harmônico (H2) recebia forte reforço pelo primeiro formante (F1) (Fig. 1), muito mais do que no estilo classicamente treinado e afirmaram que toda a característica de um belt é baseadi em um segundo harmônico (H2) forte, com binado com um alto grau de fechamento gló tico durante a vibração das pregas vocais $\mathrm{O}$ som do belting parece mais agudo, pois valoriza os formantes primários (F1 e F2) $\epsilon$ as altas frequências (SCHUTTE; MILLER 1993). Silva reforça essa afirmação ao dizer:

boca e está em torno de 250 a $700 \mathrm{~Hz}$, o segundo formante (F2) fica situado na cavidade oral entre os valores de 700 a $2.500 \mathrm{~Hz}$, contudo, esses valores aumentam consideravelmente durante o canto podendo o $\mathrm{F} 1$ chegar até $1000 \mathrm{~Hz}$ (Si4) em vozes de soprano e contralto. Para Sundberg o primeiro formante é sensível a abertura da mandíbula, ou seja, quando essa abertura aumenta, a frequência do F1 se eleva e vice-versa. Já o segundo formante, Sundberg afirma que "é sensível à forma do corpo da língua. Quando a língua comprime a parte anterior do trato vocal, na altura do palato duro, a frequência do F2 se eleva e quando essa comprime o trato vocal na região do véu palatino, a frequência do F2 diminui, especialmente se junto com esse movimento os lábios também forem arredondados" (SUNDBERG, 2015).

20 O tamanho e a velocidade de vibração das pregas vocais são determinantes para a formação da frequência fundamental e também por diversas frequências parciais que são múltiplos da frequência fundamental, ou seja, se as pregas vocais vibram 100 vezes por segundo, a laringe inclui componentes que são múltiplos integrais de 100, sendo encontrados componentes de $100,200,300 \mathrm{~Hz}$ no sinal sonoro. Essas frequências parciais são conhecidas como harmônicos da frequência fundamental e ao chegar às cavidades de ressonância, possuem compatibilidade com a frequência do trato vocal. Dessa forma, estes sons que foram transferidos mais facilmente pelo trato vocal são amplificados e transformados em formantes (ZEMLIN, 2000).
O principal componente do belt é o ajuste do trato vocal. Este ajuste é conseguido de maneira intuitiva através de um processo chamado formant tuning (sintonia de formante). Quanto mais próximo um formante estiver de um harmônico, maior a amplitude (força) deste harmônico. No limite do registro de peito, F1 (o primeiro formante, que define as vogais) segue $\mathrm{H} 2$ (o segundo harmônico), resultando em um F1-H2 tracking, que aumenta a projeção do $\mathrm{H} 2$, formando o timbre que caracteriza o belting (SILVA 2016, p. 2).

Figura 1 - llustração do ajuste do segundo harmônico (H2) em relação ao primeiro formante (F1) ${ }^{21}$.

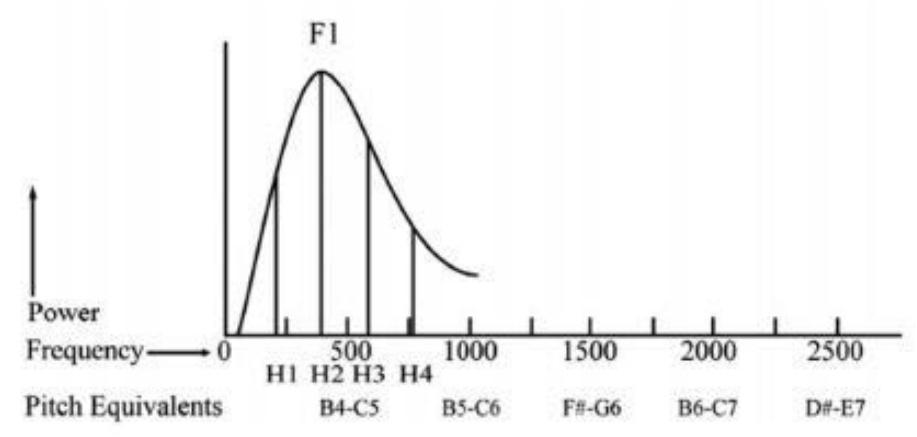

Fonte: SILVA, 2016, p. 5.

O ajuste do trato vocal na produção do belting permite uma posição laríngea neutra, ou seja, em posição natural (diferente do canto classicamente treinado onde a laringe deve estar abaixada). Segundo White essa posição neutra da laringe, combinada com a região mais próxima da fala, confere ao belting sua característica de um som mais "natural" (WHITE, 2011). Popeil observou que no belting "...o palato mole é mantido um pouco mais baixo (que no canto clássico) e há um estreitamento de espaço entre a parte posterior da língua e a parede posterior da faringe 22 " (POPEIL, 1999, p.28) enquanto

21 Onde aparece descrito na figura 1 o "Pich Equivalents" de F1-H2 como sendo B4-C5 em nomenclatura norte-americana, entendemos como sendo B3-C4 na nomenclatura brasileira.

22 "...the soft palate is held slightly lower, and there's a narrowing of space between the back of the tongue and rear pharyngeal wall." 
que no canto clássico “...a cartilagem laríngea é bastante baixa, e há bastante espaço entre a parte posterior da língua e a parede posterior da faringe ${ }^{23 "}$ (ibidem).

Com relação a forma da boca na produção do belting, Titze e Worley observaram que essa deve ser mais larga, semelhante à um megafone tipo trompete (Fig. 2) (TITZE; WORLEY, 2009). White reforça essa idéia ao dizer que "a posição neutra da laringe e o tubo de ressonância mais curto exige um "sino" mais largo para compensar e assim, consequentemente, a forma da abertura da boca deve ser mais larga" ${ }^{24 "}$ (WHITE, 2011, p.24), além de reforçar o fato de que "geralmente o belting exige modificação das vogais na direção aberta (/ i / pode gravitar em direção à / e /, por exemplo) enquanto a modificação da vogal do canto clássico se dá em direção fechada (como / a / para / o /) 25" (ibidem).

Figura 2 - llustração do ajuste do trato vocal para belting (megafone tipo trompete) e canto clássico (megafone invertido).

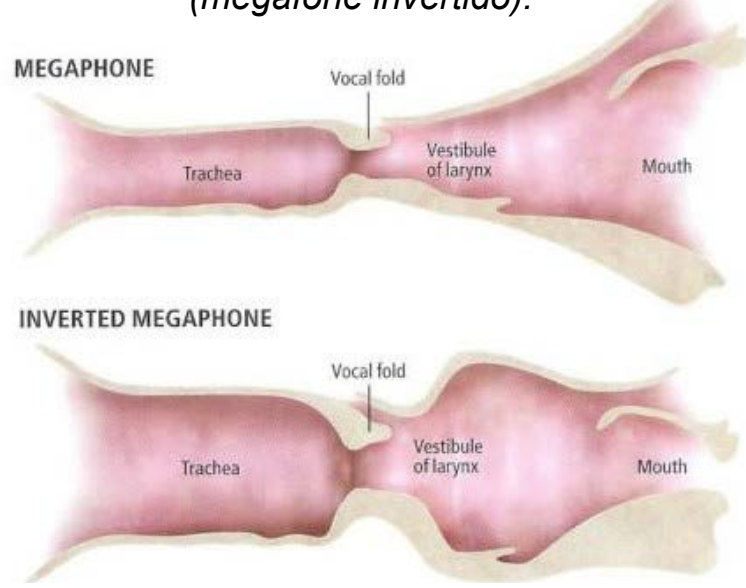

Fonte: SLIDEPLAYER, 2018.

23 "...the laryngeal cartilage is quite low, and there is quite a bit of spaciousness between the back of the tongue and rear pharyngeal wall."

24 "The neutral position of the larynx will demand a slightly higher chin level than would the lowered laryngeal position of classical singing, for obvious reasons, and the shorter resonating tube will demand a wider "bell" to compensate."

25 "generally, in belt, and vowels will require modification in the open direction (/i/ may gravitate towards /e/, for instance ), whereas in classical singing vowel modification in the closed direction ( such as /a/ towards /o/)."
Metodologia

O método escolhido para esse estudo foi o da análise comparativa. Selecionei duas canções com duas interpretações feitas em diferentes períodos. A primeira canção analisada foi "Take Me Or Leave Me" composta por Jonathan Larson para o musical Rent. Analisei duas interpretações feitas pela mesma cantora, Idina Menzel ${ }^{26}$. As interpretações foram feitas em 1996 durante as exibições de Rent e em 2006 durante um especial de 10 anos do musical. Menzel fez parte do elenco original de Rent e, por sua atuação, recebeu uma indicação ao Tony na categoria melhor atriz em musical. A segunda canção analisada foi "Maybe This Time" de John Kander, composta para o musical Cabaret. Para essa canção, analisei as interpretações de Liza Minnelli ${ }^{27}$ em 1972 e Kristin Chenoweth ${ }^{28}$ em 2015. Minnelli é considerada uma das maiores cantoras da história da Broadway e sofreu com diversos

\footnotetext{
26 Idina Kim Menzel é uma renomada cantora da Broadway. Ganhou destaque ao interpretar a personagem Maureen no elenco original do musical Rent em 1996. Menzel estudou na New York University Tisch School of the Arts onde recebeu o título de Bacharel em Belas Artes com Licenciatura em Drama em 1993. Fez sua estreia na Broadway em 1996 integrando o elenco original de Rent. Sua atuação dando vida à personagem Maureen the rendeu uma indicação ao Tony Awards na categoria de Melhor Atriz em Musical.
}

27 Liza May Minnelli é uma famosa atriz e cantora norte-americana, filha da também cantora Judy Garland e do diretor de cinema Vincent Minnelli. Iniciou sua carreira muito cedo. Quando adolescente, desistiu da escola e foi para Nova York para seguir uma carreira no palco. Minnelli atuou no filme "Cabaret" (1972), uma adaptação para o cinema do musical de mesmo nome estreado em 1966. No filme ela interpreta a personagem Sally Bowles e recebeu um Oscar por sua atuação.

28 Kristin Chenoweth, é atriz e cantora premiada com Emmy e Tony. Depois de se formar no ensino médio, Chenoweth decidiu seguir uma carreira em performance, eventualmente obtendo um Bacharelado em Teatro Musical e um Mestrado em Performance da Ópera pela Oklahoma City University. Sua carreira abrange cinema, televisão, locução e palco. É uma das maiores e mais requisitadas cantoras da Broadway e tornou-se mundialmente conhecida por sua atuação no musical "Wicked" (2003) no qual interpretava a personagem Glinda e recebeu uma indicação ao Tony Award de melhor atriz em musical. 
problemas vocais ao longo de sua premiada carreira. Já Chenoweth foi escolhida por ser um dos grandes nomes que surgiu na Broadway depois da estréia de Rent. Sua interpretação de "Maybe This Time" durante a série televisiva GLEE em 2009 e posteriormente em seu DVD "Coming Home" em 2015 é uma das mais famosas da atualidade.

Para tais análises, foram utilizadas gravações audiovisuais disponibilizadas na plataforma digital online YouTube® e, trechos das partituras das peças escolhidas.

\section{Análise}

Observando a partitura de "Take Me Or Leave Me", vemos que a melodia, escrita no âmbito vocal, encontra-se entre C3 e E4, com uma única colcheia sobressaindo em um único momento e atingindo a nota F4 no compasso 62 (Fig. 3). A linha melódica da voz se inicia no compasso 9 na nota F3. A primeira frase da linha vocal termina no compasso 10 na nota $\mathrm{C} 3$, essa é a nota mais grave de toda a canção (Fig. 4).

Figura 3 - Trecho da partitura da música "Take Me or Leave Me" de Jonathan Larson, compassos 61-63.

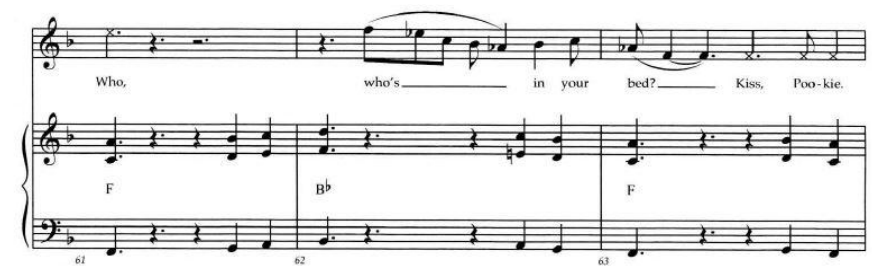

Figura 4 - Trecho da partitura da música "Take Me or Leave Me" de Jonathan Larson, compassos 09- 10.

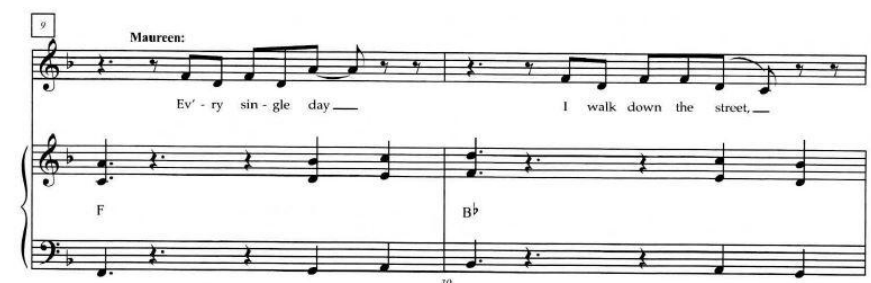

Em vídeo publicado na plataforma digital YouTube ${ }^{2}{ }^{29}$ vemos Idina Menzel interpretando, ao lado da cantora Fredi Walker, a canção "Take Me or Leave Me" em uma das apresentações do musical Rent em 1996. A canção inicia no segundo 0:07 com fala da personagem Maureen interpretada por Menzel. O canto inicia no segundo 0:16 e Menzel apresenta articulação semelhante à da fala, sua voz está rouca e aerada. No segundo 0:36 a nota a ser alcançada é A3, nesse momento, além da rouquidão, Menzel apresenta uma voz com aspecto sujo, cansada e muito estridente. A partir do minuto 1:00, em belting, ela apresenta voz cansada, apesar da boa abertura da boca, seu belting soa forçado, na garganta, como se estivesse gritando.

No vídeo publicado no YouTube® ${ }^{30} \mathrm{re}-$ ferente à interpretação feita em um especial de 10 anos de Rent, gravada em 2006, apesar da baixa qualidade da gravação, nota-se uma grande mudança na voz de Menzel.

A canção inicia no segundo 0:13 com a parte falada e já é possível notar uma voz mais leve e lisa em relação à gravação anterior. No segundo 0:31 ela canta o compasso 19 e a nota A3 é emitida com muito mais leveza em relação ao mesmo trecho da canção na gravação anterior. A partir do minuto 1:21, Menzel produz um belting claro, brilhante, metálico, frontal, com muito mais leveza e menos tensão fonatória do que na gravação de 1996.

Não encontrei relatos de que Menzel tenha sido uma das integrantes do elenco original de Rent que perdeu a voz durante o primeiro ano de apresentações do musical, porém, ao analisar sua interpretação de "Take Me or Leave Me" em 1996, ano de

29 Link do vídeo: < https://www.youtube.com/watch?v=ENeVzS9mgFc >. Acesso em 30 nov. 2018.

300 Link do vídeo: < https://www.youtube.com/watch?v=fNfYs5Bn_OM >. Acesso em 30 nov. 2018. 
estréia de Rent, é nítido o desgaste vocal apresentado pela cantora. $O$ desgaste na voz de Menzel também pode ser observado em entrevistas fornecidas por ela na época da estréia. ${ }^{31}$ Tal desgaste vocal não é percebido na gravação de 2006.

A foto 1 mostra o ajuste de boca e mandíbula feito por Menzel em 1996 durante as apresentações de Rent e, o ajuste feito em 2014 em uma apresentação do Oscar. Nota-se que na imagem de 2014, Menzel apresenta maior abertura de boca e mandíbula e a língua mais baixa e encostada nos dentes, caracterizando o ajuste do tipo megafone. Já na imagem de 1996, há uma menor abertura de boca e mandíbula e o dorso da língua encontra-se mais elevado.

Um terceiro vídeo ${ }^{32}$, também publicado na plataforma digital YouTube ${ }^{\circledR}$, mostra Menzel interpretando a canção Take Me Or Leave Me na versão de Rent para o cinema em 2005. O vídeo não foi considerado para esta análise comparativa pois, por se tratar de uma versão para o cinema, certamente existe edição na voz. Contudo, na foto 2 , extraída do minuto 1:39, podemos ver a diferença no ajuste de boca, mandíbula e língua durante a projeção da voz em belting e comparar com o ajuste feito na mesma frase da canção em 1996 (foto 1, esquerda). Nota-se que há maior abertura horizontal da boca de Menzel tanto em 2005 quanto em 2014, enquanto que em 1996 a abertura da boca é mais vertical.

31 Entrevista fornecida por Idina Menzel na época da estréia de Rent. Disponível em: < https://www.youtube.com/watch?v=qAqyMmJdbao > e <https://www.youtube.com/watch?v=C5Vn-T7MUlk> . Acesso em 03 dez. 2018.

32 Link do vídeo: < https://www.youtube.com/watch?v=mAfMZ vWJDo >. Acesso em 13 jun. 2019.
Foto 1 - Idina Menzel em belting em 1996 (esquerda) e em 2014 (direita).

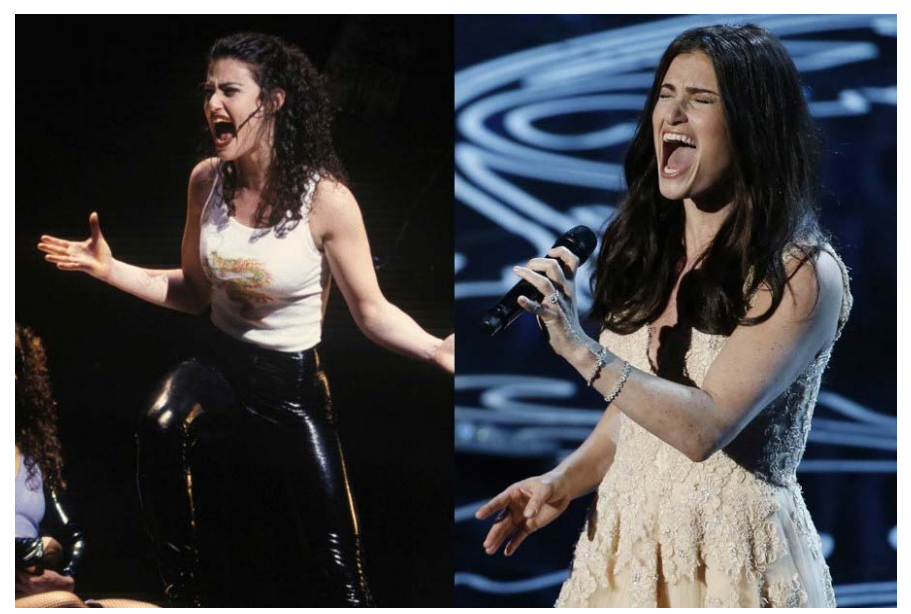

Foto 2 - Idina Menzel em belting na canção Take Me Or Leave Me de Jonathan Larson, no filme Rent em 2005.

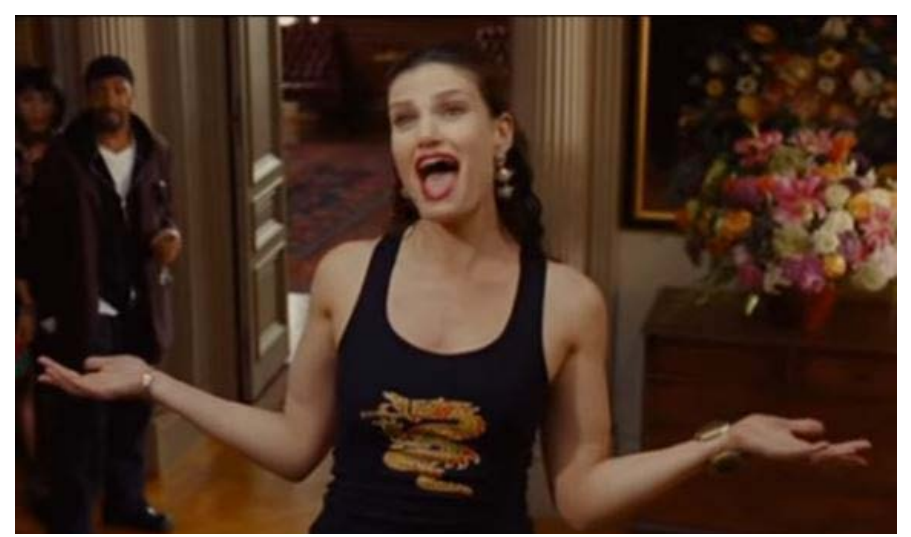

Ao observar a partitura de "Maybe This Time" nota-se (Fig. 5) que a canção também está escrita na região da fala ${ }^{33}$, a maior parte da melodia se concentra entre C3 e B3, ou seja, na região média da voz feminina. Nessa região as cantoras de musical utilizam "voz mista de peito". A partir do compasso 31 (Fig. 6), a melodia da voz passa para a segunda oitava, indo de C4 até $E 4$, sendo essa a região mais aguda da música.

Essa característica das músicas de teatro musical, de serem escritas na região da fala, foi observada por Schutte e Miller, segundo eles, os textos das canções têm

33 Região natural da fala, nas vozes femininas geralmente fica localizada entre A2 e F3. 
uma posição dominante e a naturalidade do som é altamente valorizada sendo essencial que as palavras sejam compreendidas mesmo em uma primeira audição (SCHUTE; MILLER, 1993). Silva também reforça essa observação ao dizer que no teatro musical "a voz serve ao texto" já que "o belting vem da necessidade de se cantar para plateias grandes, sem microfonação, com articulação próxima à da fala em região próxima a do calß $\beta^{4}$ " (SILVA, 2016, p.2). Ainda segundo Silva é por isso que "quando a música se separa um pouco da região da fala, a presença do belting é tão importante, pois se preserva a articulação e a emissão mais natural da fala" (idem).

Figura 5 - Trecho da partitura da música "Maybe This Time" de John Kander, compassos 5-8.

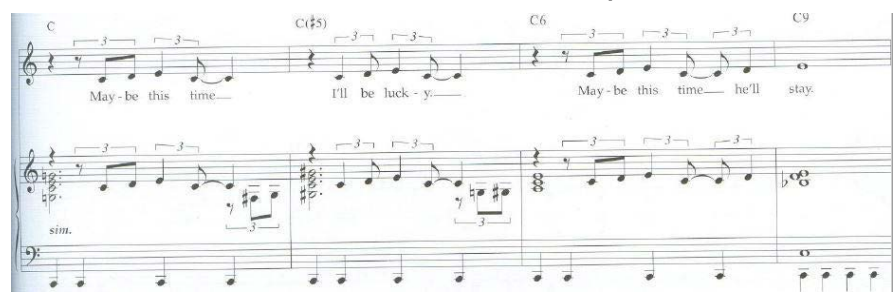

Figura 6 - Trecho da partitura da música "Maybe This Time" de John Kander, compassos 30 - 33

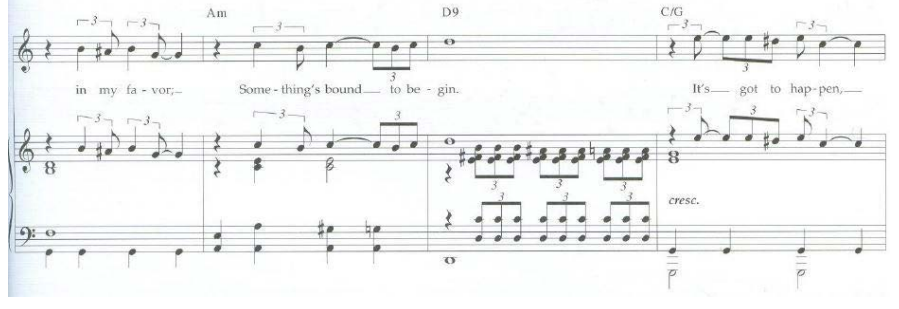

Em vídeo publicado na plataforma digital YouTube ${ }^{\circledR}{ }^{35}$, observa-se a cantora Liza Minnelli interpretando em 1972 a música "Maybe This Time" de John Kander composta para o musical "Cabaref". A canção inicia no segundo 0:13 sendo cantada na região

34 "...o chamado forte, quase gritado, o "HEY" (SILVA, 2016, p.2

35 Link do vídeo: < https://www.youtube.com/watch?v=xnY2HJyNgUc >. Acesso em 28 set. 2018. média do sub registro de peito, com voz levemente aerada, com boa articulação e semelhante a fala. No segundo 0:34 ocorre a primeira mudança de sub registro e a cantora canta em voz mista - registro típico do belting - percebe-se nesse momento que existe tensão fonatória, uso de vibrato postergado no final da frase e ela inclina a cabeça levemente para trás. No segundo 0:50 a voz sofre uma ligeira mudança de timbre ficando com a voz coberta e com timbre anasalado, como se estivesse sendo produzida dentro de um cano ou tubo, com pouco espaço de ressonância, isso parece fazer parte da atuação, parte da personagem para dar ênfase à frase. No minuto 1:27 na região média da voz, a cantora apresenta respiração ofegante e em 1:41 quando a música avança em direção ao high belting ${ }^{36}$ (C4), nota-se grande tensão fonatória, respiração ofegante, distorção vocal e vibrato postergado no final da frase. No minuto 2:29 chega o ápice da música, Minnelli inclina novamente a cabeça e o corpo para trás (foto 3 ) e produz um belting com grande esforço vocal, timbre estridente e quebra vocal ${ }^{37}$ como acontece no minuto 2:41. Ela termina a música demonstrando grande cansaço físico e vocal, com bastante vibrato e, respiração ofegante.

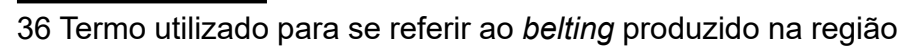
aguda da voz de peito (a partir de C4).

37 Quebra vocal é o nome utilizado para se referir ao som emitido pela voz quando ocorre uma mudança brusca de registro. A quebra vocal pode ser evitada com treinamentos e técnicas de passagem de sub registro como, por exemplo, técnicas de passagem da voz mista de peito para a voz de cabeça. 
Foto 3 - Liza Minnelli em belting na música "Maybe This Time" de John Kander para o musical Cabaret.

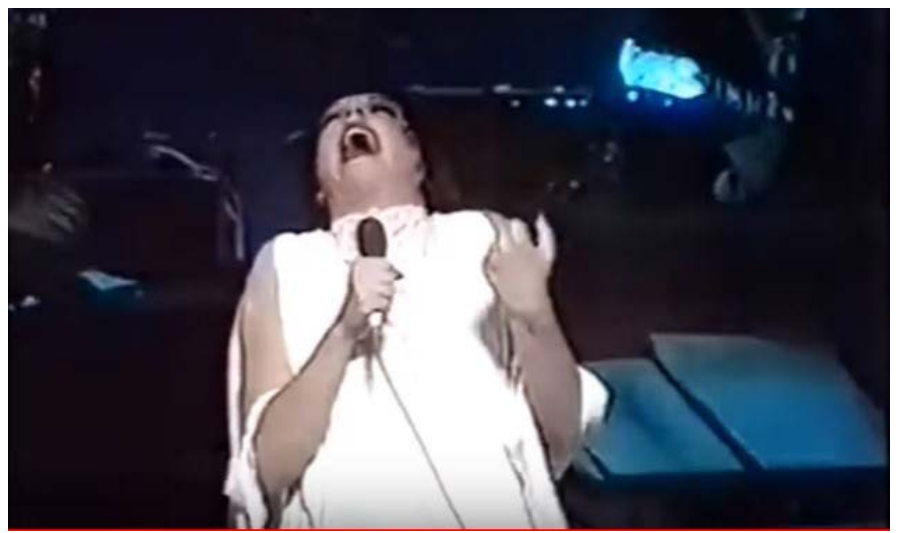

Fonte: YouTube®, 2017.

Já em outro vídeo também publicado na plataforma digital YouTube ${ }^{\circledR}{ }^{38}$, vemos Kristin Chenoweth interpretando a mesma canção (Maybe This Time) em 2015. Nota-se no segundo 0:13, que a cantora inicia a canção cantando na região média da voz e sem tensão fonatória, o som é produzido na região da fala com clareza e boa articulação das palavras. No minuto 1:29 ocorre uma mudança no ajuste do trato vocal para a projeção da voz em high belt, percebe-se a laringe elevada, maior abertura horizontal da boca e da mandíbula, e um som mais briIhante, áspero e frontal com uso moderado de vibrato no final das frases. Em 1:44 quando ocorre uma modulação no tom da música, Chenoweth retorna para a região média da voz, com boa articulação e projeção de voz mista, caracterizando um timbre brilhante e metálico. No minuto 2:14, no ápice da música, ela novamente canta em high belt (foto 4) e inclina o corpo para frente e é possível perceber o ajuste do trato vocal, a boca em forma de megafone, mandíbula bem aberta e a laringe neutra. Produz uma voz brilhante e chega a usar uma breve distorção vocal como recurso interpretativo.

38 Link do vídeo: < https://www.youtube.com/watch?v=fD1hWjffGeE >. Acesso em 03 out. 2018.
Foto 4 - Kristin Chenoweth em belting na música "Maybe This Time" de John Kander para o musical Cabaret.

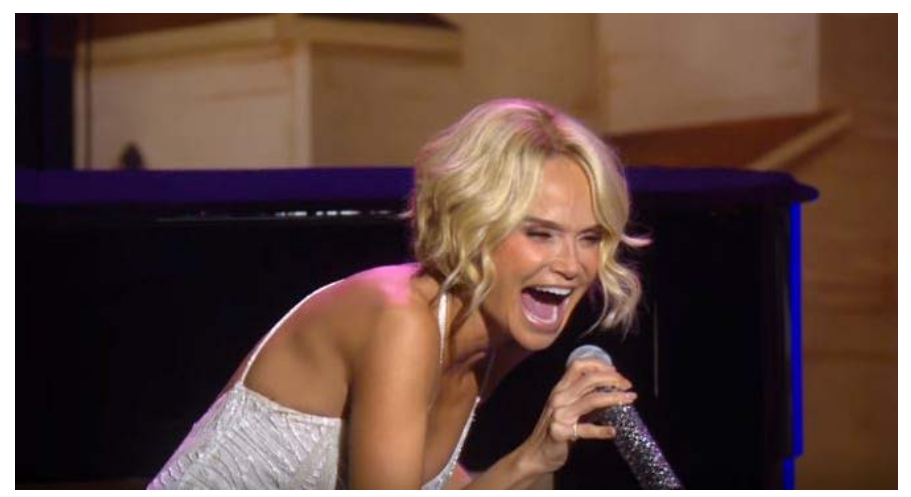

Fonte: YouTube®, 2015.

Percebe-se que em nenhum momento a atuação de Chenoweth atrapalha a interpretação da canção. Nota-se que existe tensão fonatória, porém não se percebe cansaço físico e vocal quando a música termina. Ela apresenta uma voz leve, brilhante e bem articulada durante toda a sua interpretação.

\section{Conclusão}

A análise das interpretações de Idina Menzel (1996 e 2006) mostram uma voz cansada e desgastada em 1996 e, em contraposição, em 2006 Menzel apresenta uma voz leve, ágil e brilhante. Na primeira interpretação de "Take Me or Leave Me", Menzel canta com voz rouca, produz beltings forçados e estridentes enquanto que na segunda interpretação seu belting parece ser produzido com mais naturalidade. Em ambas as interpretações sua voz apresenta um timbre nasal.

A comparação feita entre Chenoweth (2015) e Minnelli (1972) revelou uma voz mais leve e brilhante para Chenoweth em contraposição à voz aerada e pesada de Minnelli. Talvez Minnelli tenha usado a voz aerada e mais articulada como um recurso timbrístico característico da personagem. 
Gostaria de ressaltar o fato de que Minnelli havia acabado de interpretar Sally Bowles (personagem que canta a canção "Maybe This Time") no filme Cabaret, por esse motivo, creio que seu foco nessa apresentação tenha sido a atuação e a vida da personagem e não tanto as questões vocais da canção em si. Chenoweth, por sua vez, nunca interpretou Sally Bowles e em sua apresentação de "Maybe This Time" ela parece ter focado muito mais na qualidade da voz do que na atuação. Sua voz se mantém bem colocada na região da máscara desde o início da canção.

O resultado deste trabalho mostrou que havia uma tentativa de adaptar as técnicas do canto lírico para o belting nos anos 70 e 80 , tais tentativas podem ser percebidas no uso exagerado de vibratos e na abertura da boca, geralmente em forma de megafone invertido.

De acordo com a amostragem, antes de "Rent" o belting era praticado com muito esforço vocal, pouca abertura da boca e mandíbula, a abertura da boca era mais vertical com pouca ou nenhuma abertura horizontal, pouco controle respiratório, com ressonância nasal, bastante vibrato e de maneira intuitiva. O belting que conhecemos hoje apresenta um som brilhante e saudável, controle respiratório, pouco vibrato e consciência dos ajustes necessários para uma emissão saudável. Isso se deve ao crescente número de estudos acerca da técnica e ao maior número de professores especializados nesse tipo de voz.

Assim como Popeil e LoVetri declararam na entrevista fornecida à Susan Durham-Lozaw (2014), concordo com o fato de que professores de canto devem saber reproduzir a técnica que estão ensinando aos alunos e que é necessário ter conhecimento acerca da fisiologia vocal no belting. Estratégias de ressonância diferentes das utilizadas no canto clássico devem ser então adotadas, como por exemplo maior abertura da boca e mandíbula, posicionamento neutro da laringe e palato mole um pouco mais baixo que no canto clássico. Deste modo, apoio os argumentos teóricos apresentados e reforço a questão levantada por professores e pesquisadores da voz cantada nos últimos 30 anos de que o belting exige uma pedagogia baseada em exercícios técnicos diferentes daqueles das metodologias clássicas.

O mercado do teatro musical continuará exigindo maior flexibilidade vocal de seus cantores e cabe aos professores de canto e especialistas da voz, buscar meios e técnicas mais eficazes para preparar os cantores de teatro musical e CCM para o mercado de trabalho.

\section{Referências}

BENSON, E. A. Modern Voice Pedagogy: functional training for all styles. In: American Music Teacher, p. 10-17, Jun/Jul, 2018.

BORDMAN, G. American Musical Theater: A Chronicle. Terceira edição. Oxford University Press on Demand, 2001.

DURHAM-LOZAW, S. Toward a music theater vocal pedagogy for emerging adult female singers. Boston University. College Of Fine Arts. ProQuest LLC. 2014.

EDWIN, R. Belting 101. Journal of Singing, p. 53-55. 1998.

EDWIN, R. Belt is legit. Journal of Singing, v. 64, n. 2, p. 213-215, 2007.

KENRICK, J. Musical Theatre: a history. Editora Continuum. 2008. 
LARSON, J. Take Me or Leave Me. Rent School Edition. 1 partitura. Piano e voz.

MILLER, S. Strike up the band: A new history of musical theatre. Portsmouth, $\mathrm{NH}$ : Heinemann. 2007.

TRINQUESSE, E. État des connaissances sur la technique vocale du belting. In: Revue de L'association Française des Professeurs de Chant. Jul, 2009. Disponível em: < https:// www.lavoixsource.org/connaissances-de-la-technique-vocale-du-belting/ > . Acesso em 29 nov. 2018.

POPEIL, L.S. Comparing Belt and Classical Techniques Using MRI and Video-Fluoroscopy. In: Journal of Singing, vol.56, $\mathrm{n}^{\circ} 2$, p.27-29, 1999.

SCHUTTE, H. K e MILLER, D. G. Belting and Pop, Nonclassical Approaches to the Female Middle Voice: Some Preliminary Considerations. In: Journal of Voice, Vol. 7, No. 2, p. 142-150. Raven Press, Ltd., New York, 1993.

SILVA, L. S. A técnica belting para vozes masculinas: bases fisiológicas e pedagógicas para barítonos e baritenores do teatro musical norte-americano. In: Anais do XXVI Congresso da Associação Nacional de Pesquisa e Pós-graduação em Música (ANPPOM). Belo Horizonte, 2016.

SILVA, L. S. A técnica belting usada no teatro musical norte-americano e a pedagogia vocal no Brasil. Dossiê Dramaturgia Musical. Revista do Laboratório de Dramaturgia - LADI - UnB - V. 2 e 3, Ano 1, p. 197-210, 2016.
TITZE, I. R. e WORLEY, A. S. Modeling source-filter interaction in belting and high-pitched operatic male singing. In the Journal of the Acoustical Society of America. p. 1530-1540, Setembro, 2009.

WELLS, B. "Belt Technique: Research, Acoustics, and Possible World Music Applications". In Choral Journal, p. 65-77, março, 2006.

WARE, C. Basics of vocal pedagogy: the foundations and process of singing. New York: McGraw-Hill, 1998.

WHITE, A. R. Belting As An Academic Discipline. In the American Music Teacher. p. 2224, Julho, 2011.

Recebido: 00/00/2019 Aprovado: 18/07/2019 